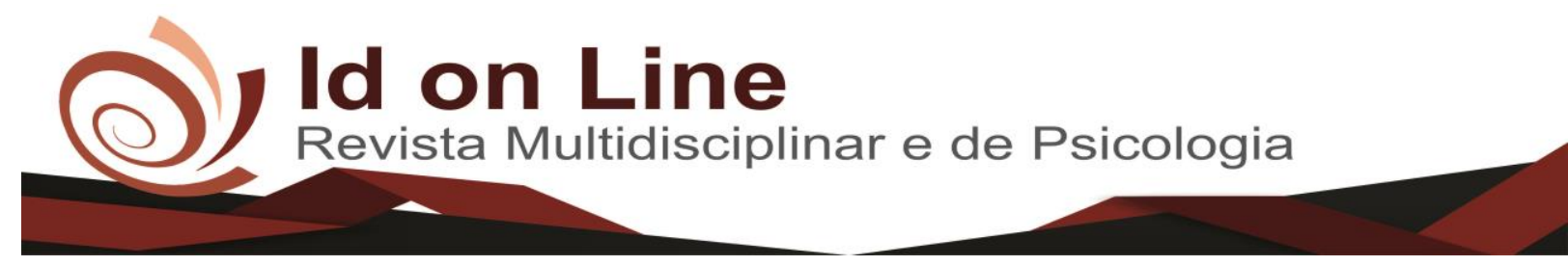

Artigo

\title{
Endividamento e Alavancagem Financeira
}

\author{
Alisson Gomes Correial'; Tiago Figueiredo de Moura Ganzarolli ${ }^{2}$
}

\begin{abstract}
Resumo: A pesquisa em questão objetivou compreender a importância que tem a controladoria na gestão de uma empresa da região do Cariri, destacando o surgimento e a evolução da controladoria, analisando de que forma esta área contribui para o desenvolvimento da empresa, estabelecendo como esta ferramenta atua na gestão de uma empresa e descrevendo quais os instrumentos utilizados pela controladoria na gestão de uma empresa. As empresas diante do atual cenário do mercado competitivo procuram cada vez mais se destacaram, na tentativa de atender às necessidades impostas pelo mercado; aumento da lucratividade e crescimento. A controladoria representa uma ferramenta que vai auxiliar os gestores das empresas para o progresso organizacional, gerando um equilíbrio na organização e auxiliando também no processo de tomada de decisões. A controladoria nas empresas atua por meio da utilização de demonstrações contábeis e também de instrumentos que vão contribuir para a análise econômicofinanceira da organização. Para alcançar os objetivos da pesquisa, utilizou-se da abordagem qualitativa, de cunho exploratório e de caráter bibliográfico e documental.
\end{abstract}

Palavras Chave: Controladoria. Ferramenta. Empresas. Instrumentos.

\section{Debt and Financial Leverage}

\begin{abstract}
The research in question aimed to understand the importance of controlling in the management of a company in the region of cariri, highlighting the emergence and evolution of control, analyzing how this sector contributes to the development of the company, establishing how this tool operates in the management and describing the instruments used by the controlling company to manage a company. Companies faced with the current scenario of the competitive market are looking increasingly to stand out in an attempt to meet the needs imposed by the market, increase their profitability and develop. Controlling represents a tool that will help the managers of the companies for the organizational progress, generating a balance in the organization and also helping in the process of making of decisions. Controlling in companies operates through the use of financial statements and also of instruments that will contribute to the economic-financial analysis of the organization. In order to reach the research objectives, a qualitative, exploratory and bibliographical and documentary approach was used.
\end{abstract}

Keywords: Controllership. Tool. Companies. Instruments.

\section{Introdução}

Devido à Revolução Industrial as empresas passaram por um grande desenvolvimento, gerando o aumento da produção e consequentemente o crescimento das mesmas. Assim, surge

\footnotetext{
1 Concludente do Curso de Ciências Contábeis do Centro Universitário Dr. Leão Sampaio - UNILEÃO. E-mail: alissongcorreia@gmail.com

${ }^{2}$ Orientador. Prof. Mestre, em Economia e Finanças, pela CAEN-UFC. Docente do Centro Universitário Dr. Leão SampaioUNILEÃO. E-mail: tiagomoura@ leaosampaio.edu.br

593 Id on Line Rev. Mult. Psic. V.13, N. 43, p. 593-613, 2019 - ISSN 1981-1179

Edição eletrônica em http://idonline.emnuvens.com.br/id
} 
a necessidade de uma ferramenta gerencial que tenha como objetivo o controle de forma rígida as operações das empresas. Surge a controladoria enquanto ferramenta que oferecia para os gestores informações precisas e eficientes para auxiliar no crescimento e desenvolvimento da organização.

A controladoria surge para atender as necessidades do empresariado, auxiliando principalmente no processo de tomada de decisão isto, é através da sua atuação enquanto observador e assessor da cúpula administrativa. A controladoria, portanto, atua por meio do fornecimento de dados e informações e de relatórios para que a empresa evolua em conjunto, tendo como principal finalidade garantir a excelência empresarial (BERTOLDI; OLIVEIRA, 2003).

Em meio a uma organização, a controladoria tem como função zelar pelo desempenho da mesma, para garantir o aumento da produtividade por meio da eficiência, gerando maior lucro e otimizando custos. A controladoria, portanto, auxilia os gestores das empresas para que estes atendem da melhor forma as exigências dos consumidores em meio a competitividade do mercado. Em uma empresa que visa alcançar o sucesso empresarial, é de primordial importância a existência do setor da controladoria.

O presente estudo tem como finalidade compreender de uma forma analítica acerca da atuação da controladoria em uma empresa situada na região do Cariri, a fim de analisar como este setor contribui para o desenvolvimento da empresa, principalmente a parte econômicofinanceira da mesma e de que forma esta auxilia os gestores para o alcance das metas e objetivos empresariais.

Possui grande relevância para a área acadêmica no que se diz respeito à base de conhecimento para a construção de novos trabalhos científicos, e também para a melhor compreensão acerca da temática abordada. Para o âmbito social, a presente pesquisa possibilita apresentar tanto para a sociedade em geral, para empreendedores que importância tem a controladoria em meio a gestão de uma empresa para que esta obtenha bons resultados e alcance os objetivos almejados.

\section{Controladoria}

A controladoria tem sua origem desde o século $\mathrm{XV}$, sendo utilizada para atender as necessidades de mercadores venezianos para o controle de custeio. Assim, no século XX, advindas das grandes corporações norte-americanas e também devido ao desenvolvimento da 
contabilidade de custo, a controladoria passa a ter uma maior importância em meio ao mercado, na tentativa de melhorar principalmente a eficiência em meio ao processo produtivo.

Surge tendo como finalidade realizar um rígido controle em relação aos negócios das empresas relacionadas, subsidiárias ou filiais. Desta forma, o surgimento desta ferramenta está ligado não somente à evolução dos meios sociais e dos meios de produção que tiveram início a partir da Revolução Industrial, mas também pela evolução que foi ocorrendo no mercado (BEUREN, 2002).

Até meados do século XVIII, a contabilidade tinha como utilidade, apenas medir e controlar o patrimônio do gestor. As empresas nesse período se desenvolvem e crescem, exigindo dos gestores e acionistas um controle central que atuasse nos diversos departamentos. A partir deste momento, surge a necessidade de haver um controle extenso e eficiente em meio as organizações.

\footnotetext{
Passada a Revolução Industrial houve uma necessidade de maiores e mais precisas informações, que permitissem uma tomada de decisão correta. Antes praticamente isso não existia, já que as operações se resumiam basicamente em comercialização de mercadorias, os estoques eram registrados e avaliados pelo seu custo real de aquisição (FAMÁ; BRUNI, 2002, p.10).
}

A Revolução Industrial pode ser considerada como marco para os sistemas administrativo e contábil. Pois, foi desde então que ocorreram mudanças em meio as organizações, tornando assim a contabilidade subdividida em financeira, de custos e gerencial.

Outro fator que possibilitou o surgimento da controladoria foi a evolução do mercado, mais sofisticado e competitivo, surgindo a partir disto a necessidade de uma ferramenta que fornecesse aos acionistas minoritários informações acerca do investimento isto, na tentativa de auxiliar no processo de tomada de decisões (LIMA, 2012).

Devido as inúmeras mudanças ocorridas no cenário econômico, a controladoria no decorrer dos tempos foi evoluindo cada vez mais, a partir da evolução do mercado, do crescimento das empresas e consequentemente devido ao aumento da demanda nessas empresas. Sua evolução se deu principalmente para adaptar-se às necessidades impostas pelo mercado e também para atender as necessidades dos gestores das empresas, que a partir de então se deparavam com problemas relacionados a comunicação interna e a coordenação da organização. Foi a partir deste momento que as empresas buscavam uma maior excelência para executar as suas operações.

Ribeiro (2011) afirma que a origem da controladoria parte das diversas transformações ocorridas na gestão das empresas que acabaram dificultando a gestão industrial das mesmas e 
exigiam uma contabilidade e controles financeiros mais eficientes. Assim, a ferramenta (controladoria) surge em meio a essas transformações enquanto elemento que vai atender a nova demanda surgida nas empresas para auxiliar principalmente no processo de tomada de decisões.

No Brasil, a controladoria surge a partir da instalação de empresas multinacionais norteamericanas no país. Sendo durante o governo de Juscelino Kubitschek (1956-1960), devido as mudanças ocorridas no desenvolvimento industrial do país, foi nesse momento que houve uma guinada da economia nacional à abertura comercial e de capitais e assim as empresas multinacionais se instalaram no Brasil (SOUZA, 2015).

Foi, através da participação das empresas multinacionais na economia brasileira que surge a Controladoria no Brasil, surgindo enquanto ferramenta advinda da instalação dessas empresas multinacionais no país e consequentemente pela a influência dessas que foi adotada a cultura norte-americana no país.

Nesse período, os profissionais da controladoria tinham por responsabilidade atuar na área financeira ou na contabilidade. Porém, devido à globalização, o avanço tecnológico e também as exigências impostas pelo mercado cada vez mais competitivo, foi necessário à melhoria dos processos e controles por parte das empresas. Desta forma, a controladoria se torna ferramenta essencial no processo de gestão de uma organização, no que diz respeito tanto a elaboração do planejamento estratégico quanto do operacional da organização.

Devido ao cenário econômico atual, as empresas sentem a necessidade de serem cada vez mais dinâmicas, na tentativa de visar atender da melhor forma as necessidades exigidas pelo mercado competitivo, tanto na parte interna da empresa quanto na externa. Trazendo para o mercado serviços eficientes. Assim, a controladoria traz para uma gestão empresarial importantes benefícios através do auxílio aos gestores para que estes atendam às exigências do mercado isto, por meio do planejamento e controle da gestão.

A controladoria, portanto, consiste no conjunto de princípios, procedimentos e métodos originados de diversas áreas e principalmente da contabilidade onde este atua em meio a gestão econômica das empresas tendo como finalidade auxiliar as empresas para que alcancem a eficácia empresarial, ao longo do processo de tomada de decisão (MOSIMANN; FISH, 1999).

Esta ferramenta colabora tanto para o crescimento quanto para o desenvolvimento de uma organização. Assim, constitui-se enquanto setor que gerador de informações fundamentais e adequadas para os gestores através da construção e manutenção dos sistemas e informações, auxiliando no processo de gestão e no processo decisório. 
operacionais, financeiras e contábeis de determinada entidade, com ou sem finalidades lucrativas (BERTOLDI; OLIVEIRA, 2003, p. 17).

Bianchi (2005), afirma que o setor da controladoria tem como função a de desempenhar um papel de facilitador, por meio do fornecimento de informações para as outras áreas da empresa, facilitando a interação entre as áreas, possibilitando que as mesmas implementem estratégias especificas as quais permitam a integração do processo de decisão estratégica de cada uma das áreas da organização visando atingir os objetivos da organização.

"A tarefa da Controladoria requer a aplicação de princípios sadios, que abrangem todas as atividades empresariais, desde o planejamento inicial até a obtenção do resultado final" (BERTOLDI; OLIVEIRA, 2003, p. 10).

A controladoria, portanto, representa importante elemento para auxiliar gestores e colaboradores no âmbito organizacional. Isto, por meio das análises financeiras das demonstrações contábeis a fim de disponibilizar aos gestores informações seguras e concretas em relação ao sistema econômico-financeira da mesma e consequentemente auxiliar no processo de tomada de decisões.

\section{Controladoria e seus Instrumentos nas Empresas}

A controladoria deve ser aplicada em empresas independentemente do seu porte. Sendo ela ferramenta na gestão empresarial, proporcionará inúmeros benefícios estes, relacionados ao planejamento, ao controle, ao registro e divulgação de resultados ligados à administração econômica e financeira da empresa. A controladoria, portanto, permitirá que a empresa alcance o sucesso empresarial, através da geração de informações seguras e necessárias, contribuindo assim para o melhor desempenho da empresa, no que se diz respeito tanto a situação financeira quanto em relação ao atendimento das necessidades impostas pelo mercado competitivo.

As funções e atividades exercidas pela controladoria podem variar de acordo com a empresa, pois, a mesma depende de diversos fatores existentes nas empresas. Dentre esses fatores estão: o porte da empresa, a diversificação das atividades da mesma, a centralização ou descentralização relacionada à administração etc. (OLIVEIRA, 1998).

A controladoria atua em meio ao processo de gestão tendo como objetivo o de auxiliar aos gestores no processo de tomada de decisões, onde todas essas decisões estejam totalmente voltadas à harmonia operacional, na busca de um objetivo almejado pela organização e com os 
gestores atuando de forma sincronizada, a fim de se gerar bons resultados utilizando o mínimo de recursos (GIONGO; NASCIMENTO, 2005).

Portanto, a controladoria representa, em uma gestão, importante aliado dos gestores para auxiliar na tomada de decisões lógicas a partir da missão e dos objetivos da organização.

A Controladoria é o ramo da ciência que cuida do patrimônio empresarial, por meio da identificação, mensuração, comunicação e decisão sobre os eventos econômicos, e, portanto, é igual a Contabilidade. A Controladoria é o exercício da função contábil em toda a sua plenitude (PADOVESE, 1997, p.30).

"A Controladoria veio para acompanhar as necessidades do empresariado, para evoluir em conjunto, para coordenar o processo de tomada de decisão". (BERTOLDI; OLIVEIRA, 2003, p.26).

\footnotetext{
A Controladoria durante o decorrer da história vem assumindo cada vez mais um papel importante na gestão das empresas, permitindo que em meio a cenários complexos, uma pluralidade de informações seja traduzida de forma que permita aos gestores e acionistas a tomada de decisões precisas, e que maximizem os resultados esperados, objetivo primário na constituição empresarial (LIMA, 2012, p.4).
}

A controladoria enquanto uma ferramenta de apoio econômico vai atuar na gestão das empresas utilizando instrumentos que vão auxiliar os gestores através de um sistema integrado, controlando as operações da mesma afim de garantir a eficácia empresarial. Será tratado portanto, acerca dos instrumentos utilizados pela controladoria em meia a gestão de empresas, elencando principalmente sobre a análise do endividamento da empresa e o quanto esta análise representa para o desenvolvimento econômico-financeiro da empresa.

\section{Alavancagem Financeira}

Para que a empresa atenda às necessidades impostas pelo mercado competitivo é necessário principalmente que esta mantenha recursos financeiros e econômicos bem equacionados.

Com base na estrutura da demonstração de resultados, a controladoria da empresa deve utilizar três tipos básicos de alavancagem. A alavancagem operacional, a alavancagem financeira e a alavancagem total. A alavancagem operacional se refere à relação entre receitas de vendas da empresa e lucros antes de juros e impostos de renda (LAJIR). A alavancagem financeira se refere a relação entre LAJIR e o lucro das ações ordinárias. E a alavancagem total 
se refere a relação existente entre a receita de vendas da organização e o lucro por ação (GITMAN, 2002).

A alavancagem se trata de um processo em que se utiliza os recursos próprios ou de terceiros para que a taxa de lucros sobre o capital próprio aumente, ou seja, se trata de um processo que tem como estratégia principal a utilização instrumentos financeiros na tentativa de aumentar o retorno potencial de certo investimento. Assim, sua utilização em meio à administração de uma empresa visa primordialmente a elevação dos resultados da mesma.

"Quando uma empresa aplica o processo de alavancagem, busca um retorno, que seja, no mínimo, suficiente para saldar as dívidas adquiridas durante o processo". (CANDIDO; CAIRES; CONVERSANI, 2014, p.34).

As empresas utilizam do princípio de alavancagem financeira pois esta representa um elemento que vai possibilitar que esta empresa obtenha maiores lucros, através da utilização de capital de terceiros (financiamentos e empréstimos). Assim, empresas lançam mão da alavancagem financeira a fim de gerar crescimento do ativo consideravelmente saudável e também para causar efeitos sobre o seu patrimônio líquido, podendo eles serem positivos ou negativos.

A alavancagem financeira, portanto, representa a relação existente entre o capital próprio e os créditos empregados em meio a uma operação financeira. Este funciona através da utilização de ativos ou recursos que possuem encargos financeiros fixos, a fim de expandir os efeitos de variação de lucro. Consiste, portanto, em um instrumento que a partir dos recursos de terceiros vai gerar resultados (positivos ou negativos) para o patrimônio líquido da empresa.

Assim, a alavancagem financeira tem extrema importância. Sua prudente utilização poderá gerar resultados positivos nos demais setores da organização. Desta forma, um excelente resultado da alavancagem nos setores citados vai proporcionar para o sistema organizacional mais lucros e menos despesas.

Entretanto, em uma empresa quanto maior for o seu Grau de Alavancagem Financeira (GAF), maior será a sua taxa de endividamento e consequentemente o seu grau de risco. Já que este grau significa que a empresa poderá aumentar seu lucro líquido por meio de uma estrutura de financiamento.

Para que seja calculado o Grau de Alavancagem de uma empresa, é necessário utilizar a seguinte fórmula:

$G A F=\frac{R P L}{R A P}$ 
Sendo também com índices de Alavancagem Financeira, o Grau de Alavancagem Operacional (GAO) e o Grau de Alavancagem Total (GAT). O primeiro representa a relação existente entre o aumento do lucro e também o aumento da receita, sendo portanto a proporção dos custos fixos relacionados aos custos variáveis. Já a GAO, representa o aumento das receitas e lucros antes dos juros, sendo essas, determinadas a partir dos ativos e também dos ganhos antes mesmo da provisão de juros.

\section{Índices de Endividamento}

As Demonstrações Contábeis estão presentes em uma empresa, na tentativa de fornecer informações detalhadas aos gestores acerca da posição patrimonial e financeira da mesma e de apresentar resultados relacionados a atuação da administração, na gestão e prestação de contas dos recursos. Em uma empresa, as demonstrações contábeis são avaliadas por meio de analises onde, um dos instrumentos desta analise são os índices, que vão permitir apresentar a real situação econômico-financeira da empresa.

Portanto, esses índices são representados pela relação existente entre grupos de contas das demonstrações financeiras da empresa que visam informar a situação econômica e financeira da mesma. Sendo utilizado esses índices enquanto técnicas para realizar a análise da situação econômica e financeira da empresa, a fim de permitir uma visão mais precisa dessa situação (MATARAZZO, 2010).

Os índices de endividamento se representam como importante fator para que a empresa amplie as suas as suas operações. Esses índices demonstram a evolução do endividamento da empresa ao longo dos exercícios, através da apresentação dos níveis de comprometimento dessa empesa em relação ao capital próprio e também o capital de terceiros, a fim de informar se tal empresa mantém uma maior utilização de recursos próprios ou de terceiros.

De acordo com Moreira (2002), estes índices de endividamento representam uma importante característica para que se tenha uma visão ampla em relação à situação econômica e financeira da organização.

Assim, os índices de endividamento são utilizados como instrumentos de análise financeira. São indicadores financeiros que contribuirão para o processo de tomada de decisões, por meio da análise do desempenho econômico-financeiro da organização, contribuindo 
também para a avaliação do equilíbrio financeiro da empresa e para a análise do grau de comprometimento da organização junto aos seus credores.

\section{Taxa de Crescimento Sustentável}

Para que a empresa conheça o próprio potencial de crescimento, é necessário que a mesma gere informações em relação as soluções de financiamento, reconhecendo suas vantagens e desvantagens. Assim, os gestores da empresa devem planejar o processo de crescimento estratégico a fim de gerar o aumento do nível de crescimento das vendas de acordo com as condições da empresa.

A Taxa de Crescimento Sustentável (TCS), representa um parâmetro que vai determinar até onde a organização pode crescer em vendas em um certo período. A TCS, consiste, portanto, em um elemento que vai trazer inúmeros benefícios para a empresa, que vai permitir que a empresa tenha seus limites em relação ao crescimento e desenvolvimento econômico.

\footnotetext{
O indicador de crescimento sustentável está baseado no produto de quatro proporções financeiras (margem de lucro, retenção de lucro, giro do ativo e alavancagem financeira), responsáveis pela determinação do nível de crescimento das vendas que pode ser suportado pela empresa, para não desequilibrar a sua capacidade de financiamento dessas atividades de vendas (FERNANDES; JONES; NAKAMURA, 2016, p. 88).
}

A taxa de crescimento sustentável possui um importante significado para empresa, no que diz respeito à apresentação de caminhos que a empresa deve seguir para manter o seu desenvolvimento. Esta taxa colabora para que a organização projete o seu patrimônio futuro a partir dos ganhos alcançados atualmente e por meio do reinvestimento dos lucros advindos da sua atividade.

A taxa, portanto, permite fornecer a empresa o quanto esta pode crescer sem haver alterações na alavancagem financeira da mesma, ou seja, mantendo o seu grau de alavancagem financeira estável, a partir da utilização apenas do seu capital próprio (HAUSHAHN, 2006).

O termo sustentável utilizado, está inteiramente ligado à capacidade de produção da empresa, sendo representada pela utilização dos bens disponíveis de forma adequada, permitindo também a garantia de que os fatores externos à empresa não interfiram de forma alguma em meio ao ciclo de vida da mesma (ANDRADE, 2001).

A TCS portanto, é calculada através da seguinte fórmula: 


$$
T C S=\frac{\text { Lucros retidos }}{\text { PL no início do período }}
$$

Assim, o crescimento sustentável em uma organização possibilitará que a mesma se desenvolva positivamente no mercado isto, por meio de estratégias que visem principalmente o seu crescimento utilizando apenas os fundos gerados internamente, disponibilizando para os gestores da empresa variáveis que determinem de que forma a empresa pode crescer e se desenvolver.

\section{Termômetro de Kanitz}

A contabilidade utiliza as demonstrações financeiras para a análise dos dados econômico-financeiros das organizações para avalição do desempenho financeiro das mesmas e também para a previsão de situações futuras. Através dos resultados obtidos por meio das análises financeiras da empresa, os gestores mantém conhecimento acerca da sua estabilidade financeira e também se a sua empresa está saudável financeiramente para permanecer no mercado. $\mathrm{O}$ instrumento utilizado para diagnosticar problemas futuros ligados à estabilidade financeira e a sua sobrevivência no mercado é o Termômetro de Kanitz (ou Termômetro de Insolvência).

O Termômetro de Kanitz surge enquanto método criado por Stephen C. Kanitz, a partir de um exame estatístico de dados colhidos de empresas que faliram, a fim de criar um instrumento que meçam os níveis de solvência das empresas. A análise da solvência de uma empresa é realizada através das demonstrações contábeis, utilizando tais resultados em cálculos de índices e quocientes auxiliando tanto no meio interno da empresa, quanto o meio externo (GOMES et al., 2015).

Através desta análise é possível diagnosticar se esta empresa está ou não com capacidade financeira para cumprir com seus compromissos e obrigações bem como se esta corre risco de falência. Desta forma, a análise de solvência representa um importante fator para a empresa que quer permanecer no mercado, pois vai permitir aos gestores, possibilidades de reverter a situação no caso de insolvência.

O Termômetro de Kanitz é um instrumento utilizado para prever a possibilidade de falência de empresas. A sua utilização tem sido, via de regra, relativa a empresas isoladas. Procura-se analisar se determinada empresa tem possibilidade ou não de falir, principalmente a curto prazo (ASSIS; MARTINS, 2017, p. 64). 
A partir dos resultados obtidos por meio deste método os gestores mantém o conhecimento em relação as condições financeiras da empresa para a sua permanência no mercado.

\section{Análise Financeira em uma Empresa na Região do Cariri}

A partir da análise financeira realizada com dados coletados utilizando o Balanço Patrimonial (BP) e a Demonstração do Resultado do Exercício (DRE) dos anos de 2016 e 2017 de uma empresa do ramo de calçados situada na região do cariri, obtivemos os resultados a seguir. As demonstrações seguem em anexo.

\section{Alavancagem Financeira e Grau de Alavancagem}

Em: 2016.

Retorno do Patrimônio Líquido

$\frac{\text { LUCRO LÍQUDO }}{\text { P.L }}=\frac{941.590,73}{2.774 .653,34}=r=0,34$

\section{Retorno do Ativo}

$\frac{\text { LUCRO OPERACIONAL }}{P . L}=\frac{1 \cdot 033 \cdot 573,93}{9.470 \cdot 090,83}=r=0,11$

$G A F=\frac{R P L}{R A P} \quad G A F=\frac{0,34}{0,11}=G A F=\mathbf{3 , 0 9}$

Em: 2017.

Retorno do Patrimônio Líquido

$\frac{L U C R O L I Q .}{P L}=\frac{1 \cdot 261 \cdot 289,52}{4 \cdot 035.086,76}=r=0,31$

\section{Retorno do Ativo}

$\frac{L U C R O \text { OPERACIONAL }}{A T I V O}=\frac{1 \cdot 309 \cdot 129,90}{13 \cdot 923 \cdot 318,06}=r=0,09$

$G A F=\frac{R P L}{R A P}=\frac{0,31}{0,09}=\mathbf{G A F}=\mathbf{3 , 4 4}$ 
De acordo com Hoji (2004), quando os resultados realizados a partir dos cálculos de grau de alavancagem resultarem em $\mathrm{GAF}=1$ este resultado representa que a empresa não faz o uso de capital de terceiros, já o resultado sendo GAF>1, representa que o capital de terceiros está valorizando o patrimônio líquido da empresa e por fim, resultando em GAF <1, representa uma alavancagem desfavorável, ou seja, não traz retorno para a empresa.

Portanto, os resultados obtidos a partir dos dados financeiros da empresa pesquisada relevam que a mesma possui um grau de alavancagem financeira favorável nos dois anos analisados (2016 e 2017), representando assim que a empresa em questão utiliza de capita de terceiros que valorizam o seu PL, gerando o desenvolvimento econômico da empresa. Porém, apesar de resultar em números satisfatórios, o ano de 2016 apresentou um valor de grau de alavancagem inferior ao ano seguinte. Em ambos os períodos analisados o uso do capital de terceiros contribuíram para gerar um retorno sobre o patrimônio líquido da empresa.

\section{Índice de Endividamento}

Em: 2016.

Índice de endividamento geral

$$
E G=\frac{3.570 .139,70 \times 100}{9.470 .090,82}=E G=37,7 \%
$$

Em: 2017.

\section{Índice de endividamento geral}

$\boldsymbol{E} \boldsymbol{G}=\frac{4.894 .982,04+4.993 .249,26 \mathrm{X} 100}{13.923 .318,06}=\mathbf{E G}=\mathbf{7 1}, \mathbf{0 2} \%$

A conclusão extraída a partir da coleta de dados financeiros da empresa de ramo calçadista dos dois períodos, indicou que no ano de 2016 a empresa financiou 37,7\% dos seus ativos com capital de terceiros e no ano seguinte financiou $71,02 \%$ do ativo com capital de terceiros. A partir dos resultados obtidos pode-se compreender que devido ao aumento do percentual em relação ao índice de endividamento geral, a empresa se mantém grande chance de risco e consequentemente de uma maior dependência em relação à terceiros.

Em: 2016.

\section{Composição de endividamento}

$$
\frac{P C X 100}{P C+E L P}=\frac{3.570 .130,70 X 100}{6.965 .437,48}=\mathbf{5 1}, \mathbf{2 5} \% \text { CE }=\mathbf{5 1}, \mathbf{2 5} \%
$$


Em: 2017.

Composição de endividamento
$\boldsymbol{C E}=\frac{4.894 .982,04 \mathrm{X} 100}{4.894 .982,04+4.993 .249,26} \quad \mathrm{CE}=\mathbf{4 9 , 5} \%$

A partir da análise financeira dos anos de 2016 e 2017 da empresa do ramo calçadista situada na cidade de Juazeiro do Norte-Ce, foi extraído em relação a sua composição de endividamento que no ano de 2016 a então empresa teve $51,25 \%$ de seu endividamento sobre o capital de terceiros em curto prazo e no ano seguinte esse percentual caiu para 49,5\%. Significando assim que a empresa no ano de 2017 reduziu o seu percentual de endividamento em relação ao capital de terceiros no curto prazo. Representando assim um fator positivo em relação ao desenvolvimento econômico da empresa pois, a mesma reduz o percentual de seu endividamento.

Em: 2016.

Índice exigível a longo prazo/PL

$\frac{E L P}{P L}=\frac{3.125 .306,78 \times 100}{2.774 .653,34}=\mathbf{1 1 2}, \mathbf{6 4} \%$

Em: 2017.

Índice exigível a longo prazo/PL

$\frac{\boldsymbol{E L P}}{\boldsymbol{P L}}=\frac{4.993 .249,26 \mathrm{X} 100}{4.035 .086,76}=\mathbf{1 2 3 , 7 5} \%$

Em relação ao índice exigível a longo prazo em relação ao patrimônio líquido da empresa pesquisada, foi possível extrair a partir da aplicação da fórmula que a empresa no ano de 2016 possuiu de capital de terceiros a longo prazo 112,64\% do PL e em 2017 seu percentual aumentou para $123,75 \%$.

Empresas com as características financeiras semelhantes a pesquisa, por apresentarem grande montante de ativos permanentes e fluxo de caixa estáveis após a aplicação da fórmula apresentam resultados bem elevados.

Em: 2016.

Índice de cobertura de juros

ICJ $=\frac{1.033 .573,93}{73.345,12}=$ ICJ $=\mathbf{1 4 , 0 9}$ 
Em: 2017.

Índice de cobertura de juros

$\frac{1.309 .129,90}{73.071,12}=\mathbf{1 7}, \mathbf{9 2}$

A partir das análises realizadas, a respeito dos índices de cobertura de juros da empresa do ramo calçadista foi possível extrair que a empresa possui índices favoráveis de cobertura de juros tanto no ano de 2016, quanto no de 2017. Compreendendo que no ano de 2017 esse percentual aumentou quase $4 \%$, representando assim que houve uma melhoria na empresa em relação aos índices, representando também no que diz respeito à solvência, que a empresa possui uma situação econômico-financeira satisfatória e que a partir do ICJ é possível reconhecer que se trata de uma empresa que possui mais ativos do que passivos.

\section{Termômetro de Kanitz}

Para que sejam encontrados os valores de x1, x2, x3, x4 e x 5 da fórmula do Termômetro de Kanitz, é necessário utilizar as seguintes fórmulas:

\section{Retorno sobre o PL:}

$X 1=\frac{\text { Lucro Líquido }}{\text { PL }}$

\section{Liquidez Geral:}

$X 2=\frac{\mathrm{AC}+\mathrm{ANC}}{\mathrm{PC}+\mathrm{PNC}}$

\section{Liquidez Seca:}

$X 3=\frac{\mathrm{AC}-\mathrm{EST}}{\mathrm{PC}}$

\section{Liquidez Corrente:}

$X 4=\frac{\mathrm{AC}}{\mathrm{PC}}$ 


\section{Índice de Endividamento:}

$X 5=\frac{P C+P N C}{P L}$

\begin{tabular}{|c|c|c|}
\cline { 2 - 3 } \multicolumn{1}{c|}{} & $\mathbf{2 0 1 6}$ & $\mathbf{2 0 1 7}$ \\
\hline $\mathbf{X 1}$ & 0,017 & 0,0155 \\
\hline $\mathbf{X} 2$ & 2,3265 & 1,221 \\
\hline $\mathbf{X 3}$ & 0,923 & 2,13 \\
\hline $\mathbf{X 4}$ & 0,7526 & 1,4734 \\
\hline $\mathbf{X 5}$ & 0,7953 & 0,8085 \\
\hline
\end{tabular}

Fonte: primária.

Índice de Insolvência (2016)

$\mathrm{K}=(\mathrm{X} 1)+(\mathrm{X} 2)+(\mathrm{X3})-(\mathrm{X} 4)-(\mathrm{X5})$

$\mathrm{K}=(0,017)+(2.3265)+(0,923)-(0,7526)-(0,7953)=\mathbf{K}=\mathbf{1 , 7 1 8 6}$.

\section{Índice de Insolvência (2017)}

$\mathrm{K}=(0,0155)+(1,221)+(2,13)-(1,4734)-(0,8085)=\mathbf{K}=\mathbf{1 , 0 8 4 6}$.

Foi extraído a partir da análise dos dados financeiros dos anos de 2016 e 2017 da empresa aplicando a fórmula do Termômetro de Kanitz, que a empresa pesquisada possui grande chance de ficar solvente por um certo tempo. Já que resultaram em números positivos, acima de 1 .

Kanitz (1978), afirma que quando se aplica a fórmula da insolvência utilizando os dados financeiros de certos períodos de uma empresa, quando o resultado $(\mathrm{K})$ estiver abaixo de -3 , representa que a empresa em questão se encontra em uma situação que poderá levá-la a falência. Se apresentar resultados acima de 0 e +7 , a empresa não deve se preocupar pois está na faixa de solvência, tendo resultados positivos e não correndo o risco de vir a falência por algum tempo. 


\section{Metodologia}

A pesquisa em questão tem como objetivo compreender a importância que tem a controladoria na gestão de uma empresa na região do Cariri, e quais os instrumentos que esta utiliza para auxiliar no processo de tomada de decisões de uma organização.

Para atingir os objetivos de estudo, a pesquisa utiliza abordagem metodológica qualitativa e quantitativa, de cunho exploratório e utilizando como procedimentos técnicos o uso do estudo bibliográfico e da pesquisa documental.

A pesquisa qualitativa representa uma abordagem metodológica de investigação científica que permite ao pesquisador apresentar informações acerca da realidade da problemática abordada, esse tipo de pesquisa é utilizado em pesquisas onde são usados dados narrativos como coleta de dados.

\footnotetext{
A pesquisa qualitativa não procura enumerar e/ou medir os eventos estudados, nem emprega instrumental estatístico na análise dos dados, envolve a obtenção de dados descritivos sobre pessoas, lugares e processos interativos pelo contato direto do pesquisador com a situação estudada, procurando compreender os fenômenos segundo a perspectiva dos sujeitos, ou seja, dos participantes da situação em estudo (GODOY, 1995, p.58).
}

"A pesquisa qualitativa não se preocupa com representatividade numérica, mas, sim, com o aprofundamento da compreensão de um grupo social, de uma organização, etc." (GERHARDT; SILVEIRA, 2009, p. 31).

O pesquisador utiliza a pesquisa qualitativa para obter informações de forma mais ampla e transmitir para os leitores a sua melhor compreensão em relação a temática abordada na pesquisa. As pesquisas de abordagem qualitativas podem ser divididas em: estudo descritivo, estudo exploratório e estudos explicativos.

De acordo com Marconi e Lakatos (2011), o método quantitativo tem como principal objetivo, o de avaliar com que frequência determinado fator acontece, e assim mede a quantidade que este fenômeno se repetiu, transformado as informações em números.

A então pesquisa, possui abordagem qualitativa e qualitativa de cunho exploratório para um maior aprofundamento do tema estudado e abordado.

Estudos de caráter exploratórios representam o tipo de estudo em que o pesquisador busca descobrir ideias e intuições, tendo como finalidade compreender da melhor forma acerca do tema abordado e também ganhar maior familiaridade com o tema estudado. Representa, portanto, uma pesquisa que tem como principal característica disponibilizar para o pesquisador 
maiores conhecimentos para criação de novas hipóteses (SELLTIZ; WRIGHTSMAN; COOK, 1965).

Esse tipo de pesquisa permite ao pesquisador que este ganhe maior familiaridade com a temática, compreendendo assim a realidade estudada de forma esclarecida, na tentativa de oferecer ao leitor uma visão geral em relação ao tema e assim possibilitar que haja uma compreensão complexa. A pesquisa em questão possui cunho exploratório e utiliza enquanto procedimentos técnicos, a pesquisa bibliográfica e documental.

\begin{abstract}
A pesquisa bibliográfica é feita a partir do levantamento de referências teóricas já analisadas, e publicadas por meios escritos e eletrônicos, como livros, artigos científicos, páginas de web sites. Qualquer trabalho científico inicia-se com uma pesquisa bibliográfica, que permite ao pesquisador conhecer o que já se estudou sobre o assunto (FONSECA, 2002, p.32).
\end{abstract}

Na pesquisa bibliográfica, o pesquisador utiliza de materiais científicos já produzidos e publicados em vários tipos de fontes, na tentativa de explicar para o leitor de forma mais clara e coesa sobre o tema estudado. Representa um importante tipo de pesquisa pois, o pesquisador deve buscar informações acerca do tema abordado em diversos aspectos teóricos para que se mantenha capacitado para abordar o tema desejado.

A pesquisa em questão utiliza não somente da pesquisa bibliográfica para atender os procedimentos técnicos da pesquisa e também para a construção teórica, mas, também utiliza da pesquisa documental.

A pesquisa documental recorre a fontes mais diversificadas e dispersas, sem tratamento analítico, tais como: tabelas estatísticas, jornais, revistas, relatórios, documentos oficiais, cartas, filmes, fotografias, pinturas, tapeçarias, relatórios de empresas, vídeos de programas de televisão, etc. (FONSECA, 2002, p. 32).

O pesquisador utiliza a pesquisa documental quando adere ao uso de fontes primárias para a construção da pesquisa isto, por meio da utilização da coleta de dados por meio de fontes não cientificas e também não publicadas, afim de complementar o uso da pesquisa bibliográfica, sendo elas um complemento da outra.

\title{
Considerações Finais
}

A presente pesquisa teve como objetivo compreender que importância tem a controladoria em meio a gestão de uma empresa, mais precisamente em uma empresa situada na região do Cariri, apresentando assim a temática abordada até os dias atuais e especificando quais os instrumentos utilizados pela controladoria na gestão de empresas para auxiliar os seus 
gestores no processo de tomada de decisões. Para uma maior familiaridade com a temática abordada, utilizou-se do estudo bibliográfico na tentativa de garantir uma compreensão ampla sobre o tema.

Os objetivos dessa pesquisa foram alcançados, gerando uma maior compreensão acerca da temática abordada e reconhecendo a importância que estes elementos possuem para a gestão de uma empresa. Através da análise dos dados financeiros da empresa estudada, verifica-se que os instrumentos utilizados pela controladoria auxiliam para a compreensão da situação econômico-financeira da empresa e também para a eficácia empresarial.

Pode-se compreender que para que uma empresa se mantenha de forma saudável no mercado competitivo, é necessário que esta mantenha de todos os instrumentos utilizados pela controladoria na gestão de uma organização pois, estes representam elementos que vão colaborar a empresa para o alcance dos seus objetivos empresariais e econômicos. Assim, a importância da utilização da análise de solvência e endividamento da empresa permite que o gestor mantenha de informações concretas acerca da situação econômico-financeira da empresa, prevendo situações futuras que venham a prejudicar a permanência da mesma no mercado e traçar estratégias para a resolução de situações indesejadas.

\section{Referências}

ANDRADE, Elivânio Geraldo. Crescimento sustentável: Uma aplicação financeira para empresas. Contabilidade, Gestão e Governança, v. 4, n. 2, 2001.

ASSAF NETO, Alexandre. LIMA, Fabiano Guasti.; ARAÚJO, Adriana Maria Procópio de. Uma proposta metodológica para o cálculo do custo de capital no Brasil. Revista de Administração, São Paulo, v. 43, n. 1, Jan/Fev/mar. 2008. Disponível em: http://www.institutoassaf.com.br/downloads/artigo_rausp_custo_capital_no_brasil.pdf. Acesso em: 07 out. 2018.

ASSIS, Lenize Machado de; MARTINS, Marco Antônio dos Santos. Aplicação do Termômetro de Kanitz a partir da evidenciação de indicadores econômico-financeiros de empresas listadas na BM\&FBOVESPA. Revista de gestão, sustentabilidade e negócios. Porto Alegre, v. 5, n. 1, p. 62-80, jun. 2017.

BEUREN, I. M. O papel da Controladoria no processo de gestão. In: SCHMIDT, P. (Org.). Controladoria: agregando valor para a empresa. Porto Alegre: Bookman, 2002.

BIANCHI, M. A Contro ladoria como um mecanismo interno de governança corporativa e de redução dos conflitos de interesse entre principal e agente. São Leopoldo, 2005. 
BERTOLDI, Kilian Karine Teixeira; OLIVEIRA, Rosane Furlan. Controladoria. Dissertação (mestrado) - Universidade Federal de Santa Catarina. 2003. 37p. Florianópolis, 2013. Disponível em: https://repositorio.ufsc.br/bitstream/handle/123456789/109256/CCN0108M.pdf?sequence=1. Acesso em: 07 out. 2018.

BRANCO, Adriel Martins de Freitas. Sustentabilidade Financeira e Empresarial. 2013. 136 p. Dissertação (Especialização) - Universidade de São Paulo, 2013.

CANDIDO, André Luís de Oliveira; CAIRES, Letícia da Silva; CONVERSANI, Thássio Umbelino. Alavancagem Financeira: Supermercados Conversani Guarantã Ltda - Guarantã SP. 2014. 142 f. Monografia (Bacharel em Administração) - Centro Universiarário Católico Salesiano, Lins, 2014.

CATAPAN, Edilson A.; HEIDEMANN, Francisco G. Cálculo do Custo de Capital como método de avaliar empresas: variáveis essenciais. XXII Encontro Nacional de Engenharia de Produção. Curitiba - $\quad$ PR, 2002. Disponível em: http://www.abepro.org.br/biblioteca/enegep2002_tr34_0121.pdf. Acesso em: 10 out. 2018.

COPELAND, Tom; KOLLER, Tim \& MURRIN, Jack. Avaliação de Empresas - Valuation: Calculando e gerenciando o Valor das Empresas. $3^{\text {a }}$ ed., São Paulo: Makron Books, 2002.

FAMÁ, Rubens. BRUNI, Adriano Leal. Gestão de custos e formação de preço. Disponível em: http://www.minhasaulas.com.br/ppt/CUSTOS_v1.ppt. Acesso em: 25 set. 2018.

FERNANDES, Hélio Jones; JONES, Graciela Dias Coelho; NAKAMURA, Wilson Toshiro. Taxa de Crescimento Sustentável das Empresas Brasileiras de Capital Aberto do Setor Siderúrgico que Compõem o IBRX100. RAGC, v.4, n.14, p.85-99/2016. Disponível em: http://www.fucamp.edu.br/editora/index.php/ragc/article/viewFile/802/588. Acesso em: 08 nov. 2018.

FONSECA, J. J. S. Metodologia da pesquisa científica. Fortaleza: UEC, 2002.

GERHARDT, Tatiana Engel; SILVEIRA, Denise Tolfo (org.). Métodos de pesquisa. Porto Alegre: Editora da UFRGS, 2009. Disponível em: http://www.ufrgs.br/cursopgdr/downloadsSerie/derad005.pdf. Acesso em: 12 nov. 2018.

GIONGO, Juliano; NASCIMENTO, Auster Moreira. O envolvimento da controladoria no processo de gestão: um estudo em empresas industriais do estado do Rio Grande do Sul. In: CONGRESSO INTERNACIONAL DE CUSTOS, 9., 2005, Florianópolis. Anais... Florianópolis, 2005.

GITMAN, Lawrence J. Princípios de administração financeira. 7. ed. São Paulo, Harbra 2002.

GODOY, A. S. Introdução à pesquisa qualitativa e suas possibilidades. In: Revista de Administração de Empresas. São Paulo: v.35, n.2, p. 57-63, abril 1995.

GOMES, Alana Larissa da Silva; ANDRADE, Jullyermenson da Costa; SOUSA, Josevaldo Amaral de; SOUZA, Liêda Amaral de; NETO ROCHA, Manoel Pereira da. Integrando o Termômetro de Kanitz e o modelo dinâmico de Fleuriet. Revista Científica da Escola de Gestão e Negócios - Universidade Potiguar. Ano 4, nº 2, fev/jul. 2015. 
HAUSHAHN, C. O impacto do crescimento da receita no resultado final das empresas. Dissertação (Mestrado) - Universidade Federal do Rio Grande do Sul, Escola de Administração, $2006 . \quad$ Disponível em: https://www.lume.ufrgs.br/bitstream/handle/10183/7859/000558802.pdf?sequence=1. Acesso em: 08 nov. 2018.

HOJI, M. Administração financeira: uma abordagem prática. São Paulo: Atlas, 2004.

KANITZ, Stephen Charles. Como prever falências. São Paulo: McGraw do Brasil, 1978.

LIMA, José Ediel de. Analise histórica da evolução da controladoria no contexto da economia brasileira. 2012. 67p. Universidade Federal do Paraná. Monografia. Pós-graduação do departamento de contabilidade do setor de ciências sociais. Disponível em: https://acervodigital.ufpr.br/bitstream/handle/1884/39013/R\%20-\%20E\%20-

\%20JOSE\%20EDIEL\%20DE\%20LIMA.pdf?sequence=2\&isAllowed=y. Acesso em: 25 set. 2018.

MATARAZZO, D. Análise financeira de balanços: abordagem básica e gerencial. 7. ed. São Paulo: Atlas, 2010.

MOREIRA, Lavor Heber. Análise dos Demonstrativos Contábeis Índices de Endividamento. Universidade Federal do Pará, 2002.

MOSIMANN, Clara Pellegrinello; FISCH, Sílvio. Controladoria: seu papel na administração de empresas. 2 ed. São Paulo: Atlas 1999.

OLIVEIRA, Catherine Fabiane Arruda de. O Custo de Capital e o Impacto da Estrutura de Capital sobre o Valor da Empresa. Dissertação para obtenção do título de Especialista em Finanças e Gestão Corporativa. Universidade Candido Mendes. 2010. 47 p. Disponível em: http://www.avm.edu.br/docpdf/monografias_publicadas/k213181.pdf. Acesso em: 10 de out. 2018.

OLIVEIRA, Luís Martins de. Controladoria: conceitos e aplicações. São Paulo: Futura, 1998.

PADOVESE, Clóvis Luiz, BENEDICTO, Gideon Carvalho de. A controladoria como ciência e unidade administrativa. Revista de contabilidade do CRC-SP. n. 123.1997.

RIBEIRO, Silvio Paula. A Controladoria e os mecanismos de geração de informações relacionados aos resíduos industriais: uma pesquisa bibliométrica junto às publicações do ENEGEP. 2011. Disponível em: http://www.abepro.org.br/biblioteca/enegep2011_tn_sto_143_904_19166.pdf. Acesso em 04 set. 2018 .

SANTIAGO, Diego de Lima; FERNANDES, Felipe Gustavo Lenharo; HIIBNER, Jéssika Prado; FOGLIO, Marcelo. Captação de Capital de Terceiros. Dissertação para obtenção de título de graduado. Centro Universitário Católico Salesiano Auxilium. Lins- SP, 2012. Disponível em: http://www.unisalesiano.edu.br/biblioteca/monografias/54887.pdf. Acesso em: 16 out. 2018.

SELLTIZ, C.; WRIGHTSMAN, L. S.; COOK, S. W. Métodos de pesquisa das relações sociais. São Paulo: Herder, 1965. 
SOUZA, Cristiane Terezinha Domingues de. A evolução da controladoria: Um estudo no Brasil. Dissertação para obtenção do título de mestre. Universidade Federal do Rio Grande do Sul (UFRGS). Pós-graduação. Monografia. 2015. Disponível em: https://lume.ufrgs.br/handle/10183/149351. Acesso em: 25 set. 2018.

\section{Como citar este artigo (Formato ABNT):}

CORREIA, Alisson Gomes; GANZAROLLI, Tiago Figueiredo de Moura. Endividamento e Alavancagem Financeira. Id on Line Rev.Mult. Psic., 2019, vol.13, n.43, p. 593-613, 2019. ISSN: 19811179.

Recebido: 23/11/2018;

Aceito: $26 / 11 / 2018$ 